\title{
Fracture Behaviours in Compression-loaded Triangular Corrugated Core Sandwich Panels
}

\author{
N.Z.M. Zaid ${ }^{1,}$, M.R.M. Rejab ${ }^{1}$, A.F. Jusoh ${ }^{1}$, D. Bachtiar ${ }^{1}$, J.P. Siregar ${ }^{1}$, and Zhang Dian \\ ping $^{2}$ \\ ${ }^{1}$ Faculty of Mechanical Engineering, Universiti Malaysia Pahang, 26600 Pekan, Pahang, Malaysia \\ ${ }^{2}$ School of Mechanical Engineering, Ningxia University, Yinchuan 750021, China
}

\begin{abstract}
The failure modes occurring in sandwich panels based on the corrugations of aluminium alloy, carbon fibre-reinforced plastic (CFRP) and glass fibre-reinforced plastic (GFRP) are analysed in this work. The fracture behaviour of these sandwich panels under compressive stresses is determined through a series of uniform lateral compression performed on samples with different cell wall thicknesses. Compression test on the corrugated-core sandwich panels were conducted using an Instron series 4505 testing machine. The post-failure examinations of the corrugated-core in different cell wall thickness were conducted using optical microscope. Load-displacement graphs of aluminium alloy, GFRP and CFRP specimens were plotted to show progressive damage development with five unit cells. Four modes of failure were described in the results: buckling, hinges, delamination and debonding. Each of these failure modes may dominate under different cell wall thickness or loading condition, and they may act in combination. The results indicate that thicker composites corrugated-core panels tend can recover more stress and retain more stiffness. This analysis provides a valuable insight into the mechanical behaviour of corrugatedcore sandwich panels for use in lightweight engineering applications.
\end{abstract}

\section{Introduction}

A corrugated-core sandwich panel consist of a corrugated sheet positioned between two thin skins is its high strength-to-weight ratio [1]. The corrugated-core serves to keep the skins apart as well as stabilising the component by resisting vertical forces. This design also enables the complete structure to act as a single thick plate as a virtue of its high shear strength [2]. The second feature shows outstanding ventilation characteristics, avoiding humidity retention that is common in cellular core materials (e.g. polymeric foams, honeycombs) [3-5].

The failure mechanisms studied in composites can vary greatly from thin to thick ones. For composites, the notion of being thick should be described in a manner more than that of uniform materials. Even though the former governs the probability of global buckling at the structural level, the later represents the number of plies in the laminate and would effect its failure behaviour at a microscopic scale, which is more unpredictable and unavoidable. This can be known from the fact that thick composites frequently improve more complex fracture modes than those in thin composites. The thick composite is laminated by the relative number of plies. Both the number of ply interface and the whole interfacial area are

\footnotetext{
*Corresponding author: nzakiahmz@gmail.com
} 
raised in proportion to the thickness, both increasing the chance of interfacial defects and delamination. From a statistical phenomenon point of view, the possibility of containing more and larger defects increases when a composite becomes thick. The compressive strength tends to decrease with an increased thickness, despite the fact that an accurate experimental validation is difficult due to the wide scatter in the results [6]. Compressive failure is a result of fibre instability sensitivity to fibre misalignment. Thicker composites contain more layers of fibre and a higher chance of greater misalignment [7].

In this paper, corrugated-core sandwich panels based on three varying materials are studied under the compression loading. Particular attention will focus on establishing the fracture modes during compression loading.

\section{Corrugated-core sandwich panels}

Three types of material have been investigated in the study, an aluminium alloy 2024-O (AL), a woven carbon fibre reinforced plastic (CFRP) and a fabric-type glass fibre reinforced plastic (GFRP). In order to get a repeatable and uniform corrugation, the sheets were prepared using a special $45^{\circ}$ triangular profile with an effective surface of fabrication of $210 \mathrm{~mm}$ by $240 \mathrm{~mm}$. Fig. 1 shows the mould, which was made from mild steel, with a nominal cell height of $10 \mathrm{~mm}$ height and cell length of $20 \mathrm{~mm}$.

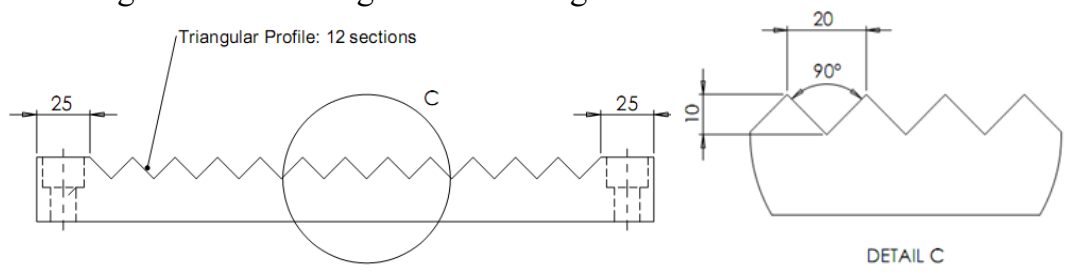

Fig. 1. Assembly drawing of the corrugated mould.

The composite corrugation was fabricated using a corrugated mould by curing it using compression mould machine. The sample was removed from the mould when the hot press cooled to a temperature below $60^{\circ} \mathrm{C}$. The corrugated core was then bonded between the two skins using a strong epoxy adhesive (Araldite $420 \mathrm{~A} / \mathrm{B}$ ). The corrugated sandwich sheet was then heated in an oven at a temperature of $120^{\circ} \mathrm{C}$ for approximately 1 hour in order to cure the adhesive. The structure was cut into test samples with dimensions of $100 \mathrm{~mm}$ (length) and $25 \mathrm{~mm}$ (width).

Fig. 2 shows a typical corrugated-core sample consisting of five repetitions of a triangular unit cell. In this investigation, the unit cell was based on a triangular profile. The geometric parameters plotted in the Figure 2 are as follows: $\theta$ and $\beta$ are the internal angle of the unit cell; $T$ is the height of the core; $H_{U}$ and $H_{L}$ are the upper and lower thicknesses of the skins, correspondingly; $H$ is the average thickness of the inclined core members, i.e. the wall thickness; $x$ is the length of the unit cell; and $w$ is the width of the sample. In this study, the value of $x$ is $20 \mathrm{~mm}$ length while $\theta$ and $\beta$ are set to $45^{\circ}$ and $90^{\circ}$, respectively. The width of all of the specimens was $25 \mathrm{~mm}$. 

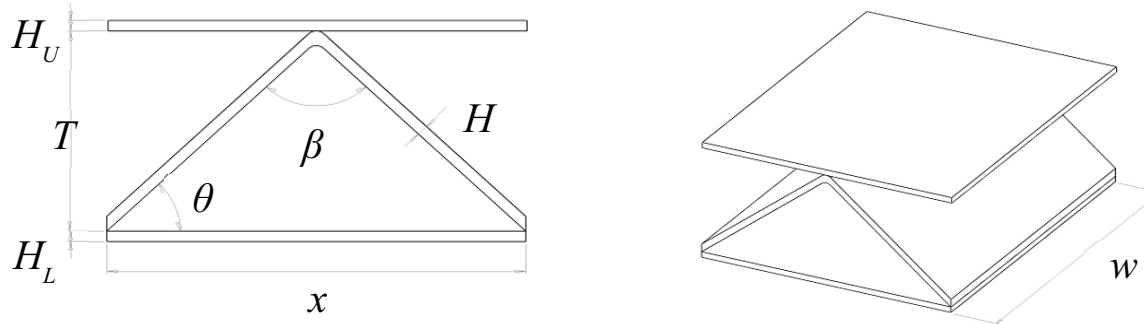

Fig. 2. Geometry of the corrugated-core sandwich panel.

\section{Experimental work}

Compression tests on the corrugated-core sandwich panels were operated using an Instron series 4505 testing machine. All the test specimens were make in a rectangular form ( $25 \mathrm{~mm}$ width $\mathrm{x} 100 \mathrm{~mm}$ length), with different web thicknesses.
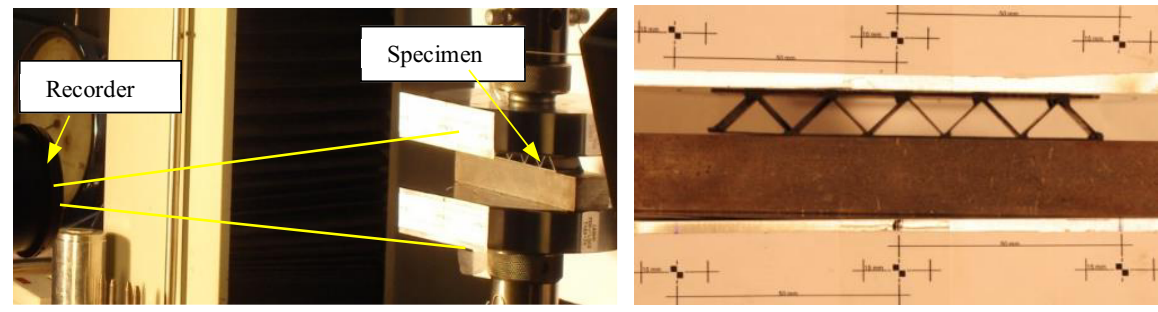

Fig. 3. Compression test set-up with the displacement measurement system.

Fig. 3 displays a specimen positioned between the platens of the test machine, with uniform lateral compression at a quasi-static loading rate of $1 \mathrm{~mm} /$ minute. A highresolution displacement measurement system was used to gather displacement data as well as capturing the resulting images. The load-displacement trace was recorded until the specimen was entirely crushed.

\section{Results and discussion}

The experiments showed that there is a fundamental difference in the behaviour of the different panels and their respective responses are considered separately below.

\subsection{Aluminium alloy corrugated-core.}

A typical load-displacement trace for an AL corrugated-core sandwich panel is showed in Fig. 4. The deformed shapes were recorded by high speed video camera. Upon loading, the specimen shows a nonlinear response during the initial loading stage. This may partly be attributed to effects associated with the machine compliance and, perhaps more significantly, to the fact that closer inspection revealed that both skins were not fully parallel to each other. As a result, the initial deformation of the panel is influenced by the flattening of these skins. After this initial "stiffening", the specimen responds in a linear fashion (as in point A) to the first peak in the load, with deformation being symmetrical about the axis of loading. After reaching the maximum peak load, one of the struts in the corrugated-core was partially bent and as a result, the overall stiffness of the specimen decreased, the load required to further deform the panel steadily decreases due to the 
transmission of localised buckling in the corrugated-core. The response then becomes progressively nonlinear (point B). This is followed by a sudden drop in the applied load as the panel loses stability due to plastic buckling.

At point $\mathrm{C}$, the corrugated-core takes on a trapezium shape, and the applied load increases, due to the interaction between the surfaces of the deformed struts and the flat skins. Finally, point D shows the corrugated-core has been completely densified, where both the skins and corrugated-core are flattened and in some cases the sides of edge are debonded.
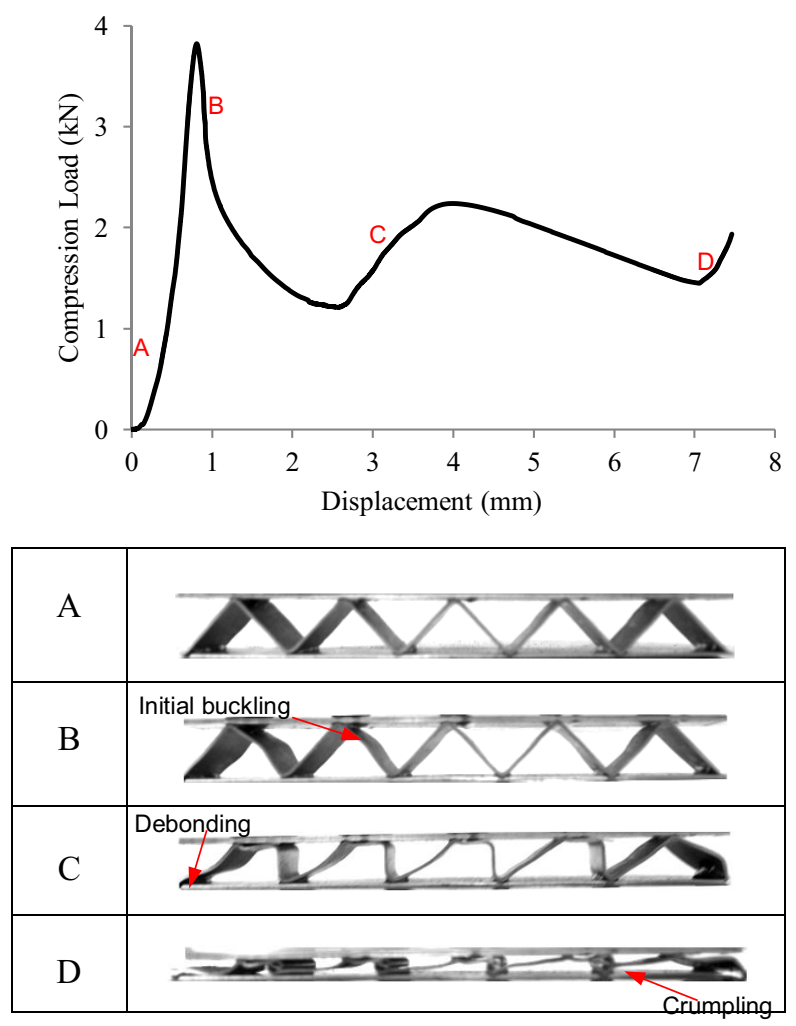

Fig. 4. Typical load-displacement curve showing progressive damage development in an AL corrugated-core sandwich panel with five unit cells.

\subsection{Glass fibre-reinforced plastic}

The GFRP corrugated-core sandwich panel exhibited a brittle behaviour, involving crushing under the compressive load as presented in Fig. 5. 

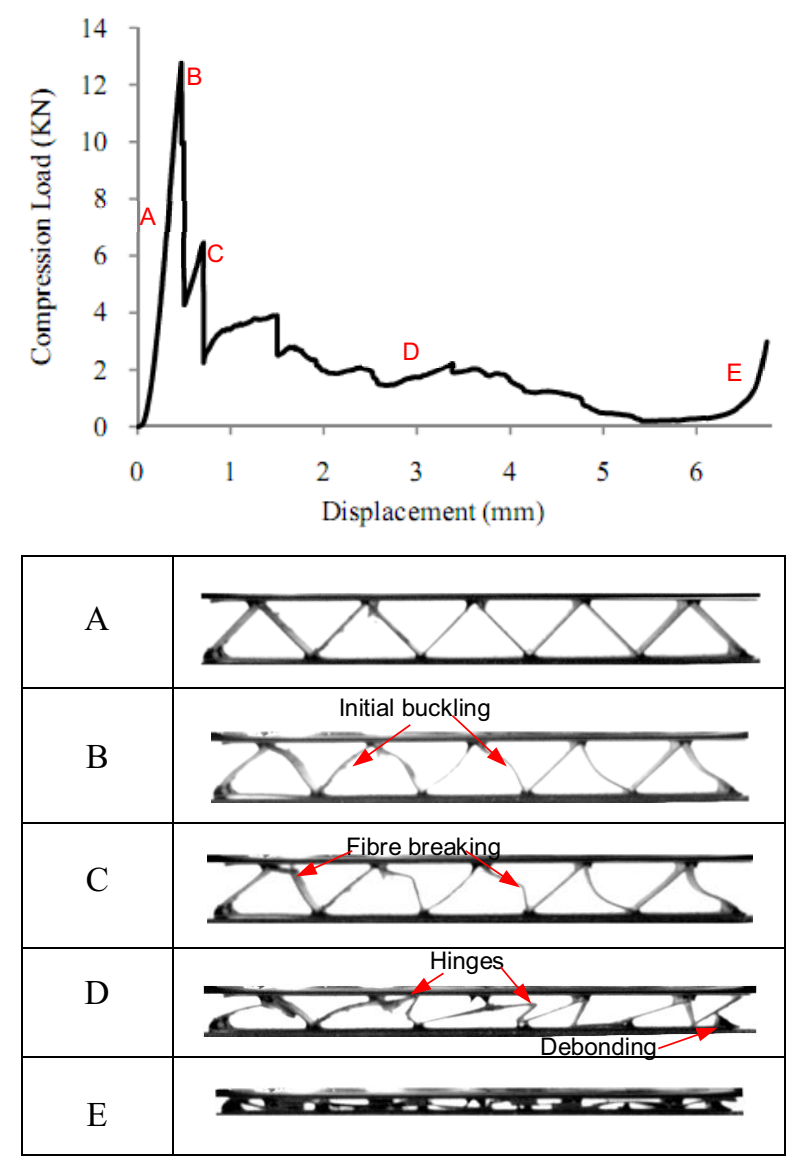

Fig. 5. Typical load-displacement curve with progressive damage development in a five unit cell GFRP corrugated-core sandwich panel.

At the point B, initial cell wall buckling was visible, followed by a compression fracture at the peak load. The drop in the load-displacement diagram is steeper than in the AL sample due to the different failure mechanisms involved (points $\mathrm{C}$ and $\mathrm{D}$ ): here, failure involves the formation of hinges in the middle of the cell wall after fibre fracture, debonding of the adhesive between the surfaces and continuous crushing after failure at the cell wall from the upper to lower skins. Finally, at point E the corrugated-core is completely crushed, where both the skins and the core are flattened.

Fig. 6 shows the relationships between the compression strength and stiffness for differe nt GFRP cell wall thicknesses. 


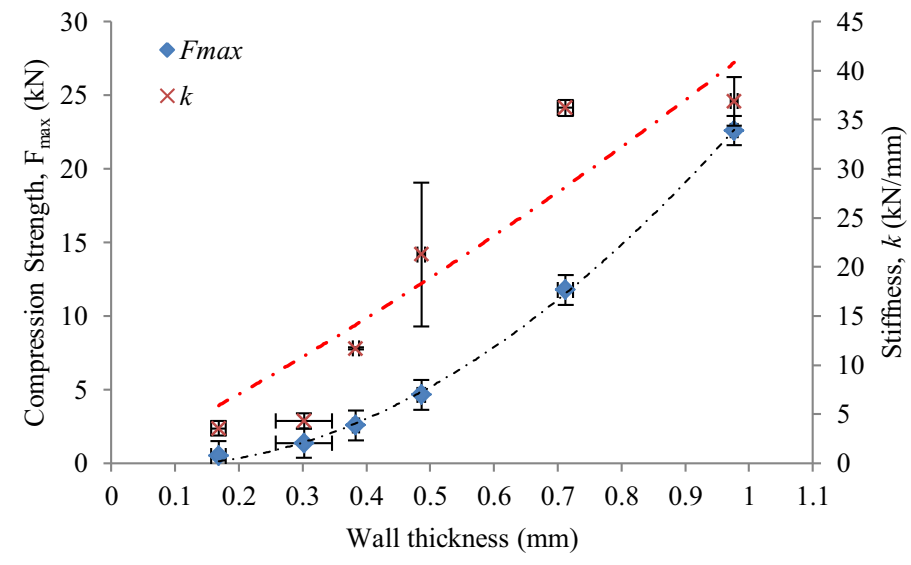

Fig. 6. Compression strength and stiffness responses to cell wall thickness of GFRP corrugated-core sandwich panels.

Table 1 displays that the failure modes and stiffness's of the 10-ply GFRP panel are quite different compared with those in the thinner specimens. The stiffness of the 10-ply sample is similar to 7-ply specimen, where the changes of the corrugation shape from sharp edges (triangular profile) to sinusoidal were observed following the fabrication process. Initial delamination damage on the wall edge associated with the demoulding process also may have contributed to the stiffness reduction.

Table 1. Post-failure examinations of GFRP corrugated-core in different cell wall thickness using optical microscope.

\begin{tabular}{|c|c|c|}
\hline Observation & Magnification (20x) \\
\hline $\begin{array}{c}\text { 3-ply of GFRP with an } \\
\text { average } H=0.30 \mathrm{~mm} \text {, failure } \\
\text { starts with buckling followed } \\
\text { by fibre breakage }\end{array}$ & Magnification (40x) \\
\hline $\begin{array}{c}\text { 5-ply of GFRP with an } \\
\text { average } H=0.49 \text { mm, failure } \\
\text { starts with buckling followed } \\
\text { by hinges and fibre breakage }\end{array}$ \\
\hline $\begin{array}{c}\text { 7-ply of GFRP with an } \\
\text { average } H=0.71 \text { mm, failure } \\
\text { starts with buckling followed } \\
\text { by fibre breakage and } \\
\text { delamination }\end{array}$ \\
$\begin{array}{c}\text { 10-ply of GFRP with an } \\
\text { average } H=0.98 m m, \text { failure } \\
\text { mode is dominated by } \\
\text { delamination damage from } \\
\text { the wall edges }\end{array}$
\end{tabular}




\subsection{Carbon Fibre-Reinforced Plastic}

The failure mechanisms in the CFRP corrugated-core under compression loading are shown in Fig. 7 where initial failure was dominated by cell wall buckling. The load-displacement plot is steeper than that for the AL corrugated-core and the post-damage failure modes are similar to the GFRP corrugated-core.
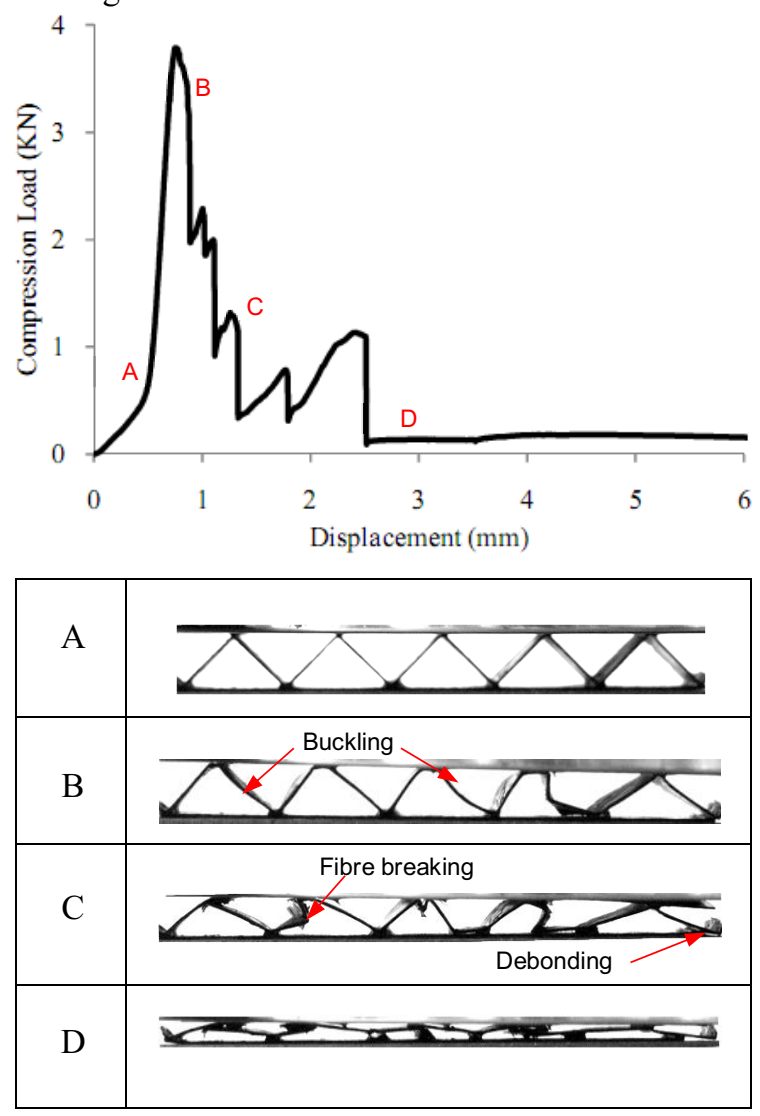

Fig. 7. Typical load-displacement curve with progressive damage development in five unit cells of CFRP corrugated-core sandwich panel.

Fig. 8 shows the relationship between the compression strength and stiffness for the different cell wall thicknesses. Regarding the stiffness response, there is considerable scatter in the data due to significant variations in the cell wall thickness. This reduced the rigidity of the strut members.

Table 2 shows the post-failure images of the fractured CFRP specimens where it can be seen that in addition to the fibre instability failure mode, other damage mechanisms such as matrix cracking and splitting are present. In most specimens, especially the thicker samples, final fracture (delamination) was located near the wall edge. In the 6-ply CFRP, initial debonding affected the global stiffness of the panels. It is believed that defects during the fabrication process, such as fibre waviness, variations in the fibre volume fraction may also have contributed in reducing the stiffness of the panels. 


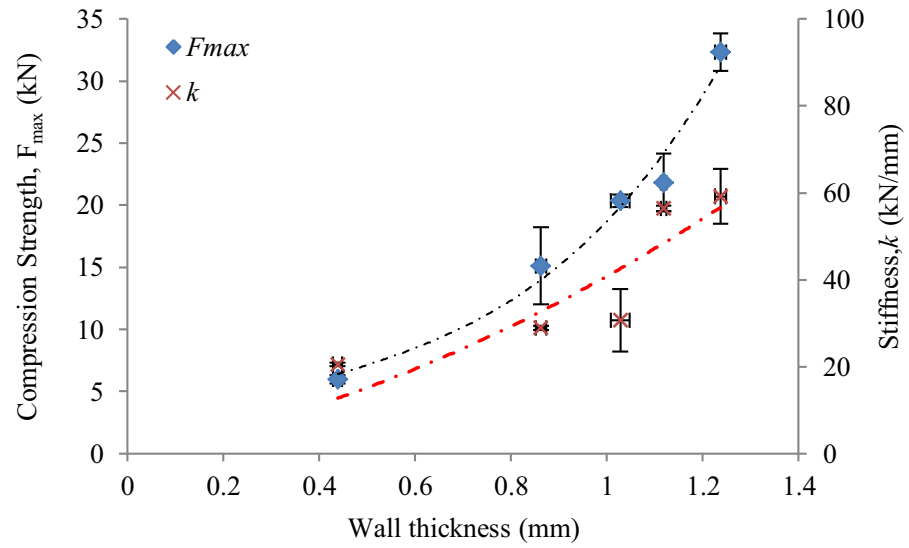

Fig. 8. Compression strength and stiffness responses of CFRP corrugated-core sandwich panels as a function of cell wall thickness.

Table 2. Post-failure examinations of CFRP corrugated-core in different cell wall thickness using optical microscope.

\begin{tabular}{|l|l|}
\hline Observation & Magnification (20x) \\
2-ply of CFRP with an \\
average $H=0.44 \mathrm{~mm}$, \\
failure starts with \\
buckling followed by \\
hinges and fibre breakage
\end{tabular}

\section{Conclusions}

The compressive responses and failure mechanisms of corrugated-core sandwich panels with three different materials subjected to uniform lateral compression were investigated both experimentally and numerically. Failure modes for different cell wall thickness of GFRP and CFRP corrugated-core panels also have been examined in this study. From the observations, it is found that initial failure in the panel was dominated by the instability of the struts when the cell wall starts to buckle. Four modes of failure were described in the results: buckling, hinges, delamination and debonding. Each of these failure modes may dominate under different cell wall thickness or loading condition, and they may act in combination. The results indicate that thicker composites corrugated-core panels tend can 
recover more stress and retain more stiffness. However, results also showed that thicker panels (10-ply GFRP and 6-ply CFRP) are less stiff. This is not because of the thickness effect but mainly because of the geometry changes at the core edges from the triangular shape to sinusoidal during the lamination process.

The authors are grateful to the Ministry of Education Malaysia for funding this research (FRGS/1/201 4/TK01/UMP/02/3).

\section{References}

1. H.G. Allen, Analysis and design of structural sandwich panels (Pergamon, Oxford, 1969).

2. F. Cote, V. S. Deshpande, N. A. Fleck, A. G. Evans, Int. J. Solids Struct., 43, 6220 (2006).

3. M.R.M Rejab, W.J. Cantwell, Compos. Part B-Eng., 47, 267 (2013)

4. Y.C. Zhang, S.L. Zhang, Z.L. Wang, Adv. Mat. Res., 217-218,1584 (2011)

5. G.V. Movchan, Russian Aeronautics, Iz. VUZ, 50, 439 (2007)

6. S. Fisher, K. Drechsler, S. Kilchert, A. Johnson, Compos. Part A-Appl. S., 40, 1941 (2009)

7. J. Lee, C. Soutis, Compos. Part A-Appl. S., 36, 213 (2005) 